\title{
Pengaruh Manajemen Berbasis Sekolah Dan Iklim Organisasi Sekolah Terhadap Profesionalitas Guru Smp/Mts Muhammadiyah Di Kabupaten Sorong Provinsi Papua Barat
}

\author{
Sulardi
}

STKIP Muhammadiyah Sorong

\begin{abstract}
This Research is designed to measure the influence of 1) School Based Management to The Teachers Professionality of Muhammadiyah Junior High School/Religious Junior High School In Sorong Regency, 2) School Organizational Climate to The Teachers Professionality of Muhammadiyah Junior High School in Sorong Regency and 3) It also measure the influence of The Teachers Professionality Muhammadiyah of Junior High School in Sorong Regency. The Method used in this research is analytic descriptive. The observed population is Principle and deputy, teacher, school committee, and student Muhammadiyah Junior High School/Religious Junior High School in Sorong Regency. Sample is taken through Stratified Random Sampling that consist 191 people. The data are analyzed by using correlation of regression with a computer by SPSS for Windows series program. The data are presented quantitatively through the table of frequency. While, the data are gathered by using combined techniques as questionnaire and documentation study. The first result there is a significant influence of School Based Management to The Teachers Professionality of Muhammadiyah Junior High School in Sorong Regency. The second result shows that there is significant influence of School Organizational Climate to The Teachers Professionality of Muhammadiyah Junior High School in Sorong Regency. The third result ideates that there is still significant influence of School Based Management respectively toward School Organizational Climate Muhammadiyah Junior High School in Sorong Regency. Summary, result there is a significant influence of School Based Management to The Teachers Professionality, result shows that there is significant influence of School Organizational Climate to The Teachers Professionality, and result ideates that there is still significant influence of School Based Management respectively toward School Organizational Climate at Muhammadiyah Junior High School in Sorong Regency. Suggestion, School Based Management and School Organizational Climate effective is, the more made The Teachers Professionality of Muhammadiyah Schools to pay homage to the people in Sorong Regency.
\end{abstract}

Keywords: correlation, school based managemen, school organization climate, teachers' professionalism, SMP/MTs Muhammadiyah Sorong Regency

\begin{abstract}
Abstrak: Penelitian ini bertujuan untuk mengungkap pengaruh langsung: (1) Manajemen Berbasis Sekolah terhadap Profesionalitas Guru SMP/MTs Muhammadiyah di Kabupaten Sorong (2) Iklim Organisasi Sekolah terhadap Profesionalitas Guru SMP/MTs Muhammadiyah di Kabupaten Sorong dan (3) Manajemen Berbasis Sekolah terhadap Iklim Organisasi Sekolah SMP/MTs Muhammadiyah di Kabupaten Sorong. Metode yang digunakan dalam penelitian ini adalah deskriptif analitik. Populasi adalah kepala sekolah dan wakilnya, komite sekolah, guru, dan Murid dari SMP/MTs Muhammadiyah di Kabupaten Sorong. Sampel diambil dengan teknik Stratified Random Sampling sejumlah 191 orang. Analisis menggunakan korelasi, regresi dan analisis jalur dengan menggunakan SPSS Windows series 12.0 for windows, sedang teknik pengumpulan data menggunakan kuesioner dan dokumentasi data, penyajian data dilakukan secara kuantitatif melalui tabel frekuensi. Hasil penelitian, Pertama, terdapat pengaruh yang signifikan antara Manajemen Berbasis Sekolah terhadap Profesionalitas Guru SMP/MTs Muhammadiyah di Kabupaten Sorong. Kedua, terdapat pengaruh yang signifikan antara Iklim Organisasi Sekolah terhadap Profesionalitas Guru SMP/MTs Muhammadiyah di
\end{abstract}


Kabupaten Sorong. Ketiga, terdapat pengaruh yang signifikan antara Manajemen Berbasis Sekolah terhadap Iklim Organisasi Sekolah SMP/MTs Muhammadiyah di Kabupaten Sorong. Kesimpulan, terdapat pengaruh yang signifikan antara Manajemen Berbasis Sekolah terhadap Profesionalitas Guru, terdapat pengaruh yang signifikan antara Iklim Organisasi Sekolah terhadap Profesionalitas Guru, dan terdapat pengaruh yang signifikan antara Manajemen Berbasis Sekolah terhadap Iklim Organisasi Sekolah SMP/MTs Muhammadiyah di Kabupaten Sorong. Saran, Manajemen Berbasis Sekolah dan Iklim Organisasi Sekolah yang kondusif harus ditingkatkan kualitasnya dalam membentuk Profesionalitas Guru sebagai bukti pengabdian sekolah-sekolah Muhammadiyah terhadap anak bangsa di kabupaten Sorong.

Kata kunci: Pengaruh, Manajemen berbasis sekolah, iklim organisasi sekolah, profesionalitas guru, SMP/MTs Muhammadiyah Kabupaten Sorong

\section{Pendahuluan}

Profesionalitas guru berarti seorang guru yang bekerja dengan keahlian, dan keahlian hanya dapat diperoleh melalui pendidikan khusus. Guru telah mengikuti pendidikan keahlian melalui lembaga kependidikan. Keahlian dalam pendidikan ditandai dengan diberikannya sertifikat atau akta mengajar. Akan tetapi kenyataannya masih banyak guru-guru yang belum bekerja secara professional dikarenakan masih belum memahami tentang tugas profesionalitas guru dalam pembelajaran.

Berkaitan dengan profesionalitas guru adalah kompetensi, yaitu guru yang profesional adalah guru yang berkompeten atau berkemampuan. Guru merupakan pendidik formal di sekolah yang bertugas membelajarkan siswa-siswanya, sehingga memperoleh pengetahuan, keterampilan, sikap, dan nilai yang semakin sempurna kedewasaan atau kepribadiannya.

Alasan faktual memilih profesionalitas guru SMP/MTs Muhammadiyah di Kabupaten Sorong karena kurangnya guru SMP/MTs Muhammadiyah yang memiliki: keahlian khusus, kualifikasi akademik S1/D IV, kompetensi pedagogik, kompetensi kepribadian, kompetensi sosial, kompetensi profesional, dan akta mengajar.

Dalam kerangka inilah manajemen berbasis sekolah (MBS) tampil sebagai paradigma pengembangan yang berorientasi pada kebutuhan sekolah dan kebutuhan daerah masing-masing. MBS merupakan kebijakan yang sangat strategis dalam rangka pengembangan kemampuan sekolah dan daerah yaitu mengenai prakarsa dari setiap sekolah dan daerah yang bersangkutan serta ditindaklanjuti oleh setiap tingkatan manajemen diatasnya.

MBS sangat penting dalam pengembangan sekolah karena bertujuan untuk meningkatkan efisiensi, mutu, dan pemerataan pendidikan. Peningkatan efisiensi, antara 
lain, diperoleh melalui keleluasaan mengelola sumber daya partisipasi masyarakat dan penyederhanaan birokrasi. Sementara peningkatan mutu dapat diperoleh, antara lain, melalui partisipasi orang tua terhadap sekolah, fleksibilitas pengelolaan sekolah dan kelas, peningkatan profesionalitas guru dan kepala sekolah, berlakunya sistem insentif serta disinsentif. Peningkatan pemerataan antara lain diperoleh melalui peningkatan partisipasi masyarakat yang memungkinakan pemerintah lebih berkonsentrasi pada kelompok tertentu. Hal ini dimungkinkan karena pada sebagian masyarakat tumbuh rasa kepemilikan yang tinggi terhadap sekolah ${ }^{1}$.

Kaitan masalah profesionalitas guru SMP/MTs Muhammadiyah dengan MBS adalah mengenai kurangnya peningkatan kinerja tenaga pendidik dan kependidikan melalui partisipasi dalam pengambilan keputusan juga perlu mendapat perhatian, disamping itu terkadang kurikulum pembelajaran belum sesuai dengan kondisi dan kebutuhan peserta didik, kepemimpinan kepala sekolah yang belum demokratis dan profesional juga menjadi hambatan.

Partisipasi aktif komite sekolah dan dewan pendidikan untuk turut merumuskan program-program sekolah masih sering tidak dilaksanakan, termasuk partisipasi dalam berbagai sekolah yang diharapkan menjadi narasumber, demikian juga bantuan untuk pendanaan sekolah.

Masalah-masalah tersebut di atas perlu diteliti agar menghasilkan karya ilmiah yang dapat dipertanggungjawabkan secara akademik, dan akan bermanfaat bagi pemerintah dan masyarakat.

Kurangnya profesionalitas guru yang mengajar sesuai bidangnya, Manajemen berbasis sekolah yang belum terwujud, dan suasana belajar yang belum kondusif karena banyaknya orang mabuk minuman keras dan bentrokan antar suku, dengan demikian inilah yang mendasari penulis akan mengadakan penelitian di SMP/MTs Muhammadiyah di dalam lingkungan Majelis Pendidikan Dasar dan Menengah (Majelis Dikdasmen) Pimpinan Daerah Muhammadiyah (PDM) Kabupaten Sorong Provinsi Papua Barat.

\section{Metode Penelitian}

\subsection{Desain penelitian}

Pelaksanaan penelitian ini menggunakan pendekatan kuantitatif dengan metode deskriptif, yaitu suatu pendekatan yang mempelajari tentang suatu hal atau sesuatu

${ }^{1}$ E. Mulyasa. 2007. Manajemen Berbasis Sekolah.cet.11. Penerbit : PT. Remaja Rosdakarya. Bandung. Hal. 25. 
permasalahan secara intensif mengenai latar belakang keadaan sekarang dan interaksi lingkungan suatu unit sosial, individu, kelompok, lembaga atau masyarakat guna diperoleh sesuatu pemahaman yang lebih mendalam mengenai permasalahan tersebut. Metode deskriptif merupakan metode yang memusatkan perhatian pada masalah-masalah yang aktual dengan mengumpulkan data dan informasi yang lengkap dan terperinci, kemudian di analisis sehingga dapat dikemukakan cara pemecahannya.

\subsection{Populasi dan Sampel}

\subsubsection{Populasi}

Populasi dalam penelitian ini adalah Kepala dan Wakil kepala sekolah, guru, murid, dan komite sekolah SMP/MTs Muhammadiyah di Kabupaten Sorong Provinsi Papua Barat yang berjumlah 639 orang. Hal demikian didasarkan pada wilayah generalisasi yang terdiri atas subyek atau obyek yang mempunyai kuantitas dan karakteristik/sifat tertentu untuk dipelajari dan kemudian ditarik kesimpulan sesuai dengan ruang lingkup penelitian.

\subsubsection{Sampel}

Menurut Issac dan Michael dalam Murwani $^{2}$ (tabel terlampir) dari populasi berjumlah 639 penarikan sampel dengan tingkat kesalahan $10 \%$ maka dalam penelitian ini diambil sampel sebanyak 191 orang untuk dianalisisdan 30 orang sebagai try out.

Pengambilan sampel dalam penelitian ini adalah Teknik Stratified Sampel. Teknik ini digunakan karena dalam penelitian ini memperhatikan kelompok-kelompok latar belakang anggota stakeholder yang ada, yaitu kepala sekolah dan wakilnya (3 peserta), guru (26 Peserta), murid (148 peserta) dan komite sekolah (14 peserta). Teknik ini dilengkapi dengan teknik lain, yaitu teknik random sampling.

\subsection{Lokasi dan Waktu Penelitian}

Tempat untuk penelitian ini di SMP/MTs Muhammadiyah di Kabupaten Sorong Provinsi Papua Barat. Sementara waktu penelitian ini dilaksanakan mulai bulan Maret sampai November 2010.

\subsection{Teknik Pengumpulan Data}

Teknik pengumpulan data yang digunakan adalah kuesioner dan dokumentasi.

\footnotetext{
${ }^{2}$ Santosa Murwani et. al. 2008. Pedoman Tesis dan Disertasi Program Pascasarjana Universitas Muhammadiyah Prof. DR. HAMKA. UHAMKA PRESS. Jakarta. h. 23.
} 
a) Penggunaan angket (kuisioner), yaitu merupakan teknik pengumpulan data melalui penyebaran daftar pertanyaan (angket) kepada para responden untuk diisi atau dijawab.

b) Metode Dokumentasi.

Menurut Arikunto $^{3}$ metode dokumentasi yaitu mencari data mengenai hal-hal atau variabel yang berupa catatan, transkrip, buku, surat kabar, majalah, prasasti, notulen rapat, legger, agenda, dan sebagainya.

\subsection{Teknik Analisis Data}

Data yang diperoleh dianalisa dengan teknik analisis data kuantitatif dengan menggunakan pendekatan deskriptif, dimana menggambarkan informasi atau data sebagaimana adanya. Penelitian ini menggunakan analisis data secara deskriptif dan inferensial. Analisis deskriptif terdiri atas penyajian data dengan histogram, perhitungan mean, median, modus, simpangan baku dan rentang teoretik masing-masing variabel. Analisis inferensial (uji hipotesis) dengan analisis jalur. Sebelumnya perlu diuji persyaratan analisis data, yaitu uji normalitas, homogenitas, dan linearitas regresi.

\section{Hasil Penelitian dan Pembahasan}

\subsection{Hasil Penelitian}

Variabel Manajemen Berbasis Sekolah $\left(\mathrm{X}_{1}\right)$ dengan Profesionalitas Guru $\left(\mathrm{X}_{3}\right)$. Nilai yang diperoleh sebesar 0,476 tingkat hubungan yang kuat antara variabel Manajemen Berbasis Sekolah $\left(\mathrm{X}_{1}\right)$ dengan Profesionalitas Guru $\left(\mathrm{X}_{3}\right)$. untuk membuktikan hipotesis "apakah ada hubungan yang signifikan antara variabel $\mathrm{X}_{1}$ dan $\mathrm{X}_{3}$ ”. Jika nilai probabilitas 0,05 lebih kecil atau sama dengan nilai probabilitas sig atau $(0,05 \leq \mathrm{sig})$, maka tidak signifikan. Jika nilai probabilitas 0,05 lebih besar atau sama dengan nilai probabilitas sig atau $(0,05 \geq \mathrm{sig})$, maka tidak signifikan. Tabel Correlations diperoleh variabel Manajemen Berbasis Sekolah $\left(\mathrm{X}_{1}\right)$ dengan Profesionalitas Guru $\left(\mathrm{X}_{3}\right)$ nilai sig. (2tailed) sebesar 0.000 , kemudian dibandingkan dengan probabilitas 0,05 , ternyata nilai probabilitas 0,05 lebih besar dari nilai probabilitas sig. (2-tiled) atau $[0,05>0,000]$ artinya signifikan. Terbukti bahwa Manajemen Berbasis Sekolah $\left(\mathrm{X}_{1}\right)$ berhubungan secara signifikan dengan Profesionalitas Guru $\left(\mathrm{X}_{3}\right)$.

Variabel Iklim Organisasi Sekolah $\left(\mathrm{X}_{2}\right)$ dengan Profesionalitas Guru $\left(\mathrm{X}_{3}\right)$. Nilai yang diperoleh sebesar 0,476 tingkat hubungan yang kuat antara variabel Iklim

\footnotetext{
${ }^{3}$ ibid h. 231.
} 
Organisasi Sekolah $\left(\mathrm{X}_{2}\right)$ dengan Profesionalitas Guru (X3). untuk membuktikan hipotesis "apakah ada hubungan yang signifikan antara variabel $\mathrm{X}_{2}$ dan $\mathrm{X}_{3}$ ". Jika nilai probabilitas 0,05 lebih kecil atau sama dengan nilai probabilitas sig atau $(0,05 \leq \mathrm{sig})$, maka tidak signifikan. Jika nilai probabilitas 0,05 lebih besar atau sama dengan nilai probabilitas sig atau $(0,05 \geq \mathrm{sig})$, maka tidak signifikan. Tabel Correlations diperoleh variabel Iklim Organisasi Sekolah $\left(\mathrm{X}_{2}\right)$ dengan Profesionalitas Guru $\left(\mathrm{X}_{3}\right)$ nilai sig. (2-tailed) sebesar 0.000 , kemudian dibandingkan dengan probabilitas 0,05 , ternyata nilai probabilitas 0,05 lebih besar dari nilai probabilitas sig. (2-tiled) atau $[0,05>0,000]$ artinya signifikan. Terbukti bahwa Iklim Organisasi Sekolah $\left(\mathrm{X}_{2}\right)$ berhubungan secara signifikan dengan Profesionalitas Guru $\left(\mathrm{X}_{3}\right)$.

Manajemen Berbasis Sekolah (X1) nilai konstanta (a) $=49,553$ dan beta $=0,353$ serta harga $t$ hitung dan tingkat signifkansi $=0,000$. Persamaan perhitungannya adalah: $\hat{Y}$ $=49,553+0,353 \mathrm{X}_{1}$. Artinya jika tidak peningkatan Manajemen Berbasis Sekolah, maka Profesionalitas Guru 49,553. Koefisien regresi sebesar 0,353 menyatakan bahwa setiap penambahan Manajemen Berbasis Sekolah 0,353 akan meningkatkan Profesionalitas Guru 0,353. Sebaliknya setiap penurunan Manajemen Berbasis Sekolah 0,353 akan menurunkan Profesionalitas Guru 0,353.

Iklim Organisasi Sekolah $\left(X_{2}\right)$ nilai konstanta $(a)=49,553$ dan beta $=0,200$ serta harga $t$ hitung dan tingkat signifkansi $=0,013$. Persamaan perhitungannya adalah: $\hat{Y}=$ $49,553+0,2 \mathrm{X}_{2}$. Artinya jika tidak peningkatan Iklim Organisasi Sekolah, maka Profesionalitas Guru 49,553. Koefisien regresi sebesar 0,2 menyatakan bahwa setiap penambahan Iklim Organisasi Sekolah 0,2 akan meningkatkan Profesionalitas Guru 0,2. Sebaliknya setiap penurunan Manajemen Berbasis Sekolah 0,2 akan menurunkan Profesionalitas Guru 0,2.

Uji koefisien regresi MBS $\mathrm{t}_{\text {hitung }}>\mathrm{t}_{\text {tabel }}$ atau 4,417 > 1,645, maka Ho ditolak dan Ha diterima, artinya signifikan. Jadi Manajemen Berbasis Sekolah berpengaruh signifkan terhadap Profesionalitas Guru.

Uji koefisien regresi Iklim Organisasi Sekolah ternyata $t_{\text {hitung }}>t_{\text {tabel }}$ atau 2,505> 1,645, maka Ho ditolak dan Ha diterima, artinya signifikan. Jadi Iklim Organisasi Sekolah berpengaruh signifkan terhadap Profesionalitas Guru.

Berdasarkan hasil perhitungan analisis jalur, maka memberikan informasi secara obyektif sebagai berikut: 
1. Besarnya pengaruh Manajemen Berbasis Sekolah $\left(\mathrm{X}_{1}\right)$ yang secara langsung mempengaruhi Profesionalitas Guru $\left(\mathrm{X}_{3}\right)$ adalah $0,319^{2}=0,101761$ atau $10,18 \%$.

2. Besarnya pengaruh Iklim Organisasi Sekolah $\left(\mathrm{X}_{2}\right)$ yang secara langsung mempengaruhi Profesionalitas Guru $\left(\mathrm{X}_{3}\right)$ adalah $0,273^{2}=0.074529$ atau $7,45 \%$.

3. Besarnya pengaruh Manajemen Berbasis Sekolah $\left(\mathrm{X}_{1}\right)$ yang secara langsung mempengaruhi Iklim Organisasi Sekolah $\left(X_{2}\right)$ adalah $\rho_{21}=r_{12=} 0,578$ atau 57,8\%.

\subsection{Pembahasan}

1) Pengaruh Variabel $X_{1}$ (Manajemen Berbasis Sekolah) dan Variabel $X_{3}$ (Profesionalitas Guru)

Memperhatikan dari hasil hubungan variabel $\mathrm{X}_{1}$ (Manajemen Berbasis Sekolah) dan variabel $\mathrm{X}_{3}$ (Profesionalitas Guru) membuktikan bahwa pengaruh variabel $\mathrm{X}_{1}$ (Manajemen Berbasis Sekolah) terhadap variabel $\mathrm{X}_{3}$ (Profesionalitas Guru) termasuk dalam kategori kuat. Dengan demikian dapat disimpulkan bahwa Manajemen Berbasis Sekolah harus ditingkatkan sehingga mampu meningkatkanProfesionalitas GuruSMP/MTs Muhammadiyah di Kabupaten Sorong Provinsi Papua Barat.

Berdasarkan hal tersebut di atas, maka Manajemen Berbasis Sekolah sangat berpengaruh terhadap Profesionalitas Guru, karena Profesionalitas GuruSMP/MTs Muhammadiyah di Kabupaten Sorong Provinsi Papua Barat harus dapat diperkuat dengan pelaksanaan Manajemen Berbasis Sekolah secara efektif dan efisien.

\section{2) Pengaruh Variabel $\mathbf{X}_{2}$ (Iklim Organisasi Sekolah) dan Variabel $\mathbf{X}_{3}$ (Profesionalitas Guru)}

Memperhatikan dari hasil hubungan variabel $\mathrm{X}_{2}$ (Iklim Organisasi Sekolah) dan variabel $\mathrm{X}_{3}$ (Profesionalitas Guru) membuktikan bahwa pengaruh variabel $\mathrm{X}_{2}$ (Iklim Organisasi Sekolah) terhadap $\mathrm{X}_{3}$ (Profesionalitas Guru) masih perlu peningkatan melalui dukungan pemerintah dan partisipasi masyarakat sehingga mampu meningkatkan pembangunan bidang pendidikan, hal ini dibuktikan bahwa pengaruh variabel $\mathrm{X}_{2}$ (Iklim Organisasi Sekolah) terhadap variabel $\mathrm{X}_{3}$ (Profesionalitas Guru) termasuk dalam kategori sedang ke arah kuat. Sehingga dapat disimpulkan bahwa Iklim Organisasi Sekolah perlu diperbaiki lagi sehingga mampu memberikan dukungan terhadap Profesionalitas Guru yang lebih besar.

Oleh karena itu Iklim Organisasi Sekolah perlu adanya penataan kembali agar keadaannya lebih baik. Sosialisasi baik dari pihak Majelis Pendidikan Dasar dan 
Menengah Pimpinan Daerah Muhammadiyah Kabupaten Sorong, Dewan Pendidikan Kabupaten dan DPRD Kabupaten harus serius dan terus menerus, demikian juga Pemerintah harus memfasilitasi agar Profesionalitas GuruSMP/MTs Muhammadiyah di Kabupaten Sorong menjadi kenyataan.

3) Pengaruh Variabel $X_{1}$ (Manajemen Berbasis Sekolah) dan Variabel $X_{2}$ (Iklim $\begin{array}{llllll}\text { Organisasi Sekolah) } & \text { secara bersama-sama terhadap Variabel } \mathbf{X}_{3}\end{array}$ (Profesionalitas Guru)

Jika memperhatikan hasil dari hubungan variabel $\mathrm{X}_{1}$ (Manajemen Berbasis Sekolah) dan variabel $\mathrm{X}_{2}$ (Iklim Organisasi Sekolah) secara bersama-sama terhadap variabel $\mathrm{X}_{3}$ (Profesionalitas Guru) membuktikan bahwa pengaruh variabel $\mathrm{X}_{1}$ (Manajemen Berbasis Sekolah) dan variabel $\mathrm{X}_{2}$ (Iklim Organisasi Sekolah) terhadap variabel $\mathrm{X}_{3}$ (Profesionalitas Guru) masih perlu peningkatan, hal ini dibuktikan bahwa pengaruh variabel $\mathrm{X}_{1}$ (Manajemen Berbasis Sekolah) dan variabel $\mathrm{X}_{2}$ (Iklim Organisasi Sekolah) terhadap variabel $\mathrm{X}_{3}$ (Profesionalitas Guru) termasuk dalam kategori kecil kearah sedang. Sehingga dapat disimpulkan bahwa Manajemen Berbasis Sekolah dan Iklim Organisasi Sekolah diharapkan dapat sejalan dan lebih ditingkatkan lagi sehingga mampu menambahProfesionalitas GuruSMP/MTs Muhammadiyah di Kabupaten Sorong yang lebih besar.

Dari hasil analisa tersebut diatas dapat disimpulkan bahwa Manajemen Berbasis Sekolah dan Iklim Organisasi Sekolah menambahProfesionalitas Guru yang dibutuhkan dan dapat dirasakan oleh seluruh lapisan masyarakat. Hal ini sesuai dengan kerangka pemikiran bahwa variabel $\mathrm{X}_{1}$ (Manajemen Berbasis Sekolah) dan variabel $\mathrm{X}_{2}$ (Iklim Organisasi Sekolah) baik secara sendiri-sendiri atau bersama-sama mempunyai pengaruh terhadap variabel $\mathrm{X}_{3}$ (Profesionalitas Guru) sehingga dalam menciptakan Profesionalitas Guru dibutuhkan Manajemen Berbasis Sekolah yang diikuti oleh Iklim Organisasi Sekolah sehingga Profesionalitas Guru dapat ditingkatkan sesuai dengan yang diharapkan.

\section{c) Kesimpulan dan Saran}

\subsection{Kesimpulan}

Berdasarkan hasil penelitian dan hasil analisis secara statitstik, maka dapat diambil kesimpulan sebagai berikut:

1. Terdapat pengaruh yang signifikan Manajemen Berbasis Sekolah terhadap Profesionalitas Guru SMP/MTs Muhammadiyah di Kabupaten Sorong. Adanya 
pengaruh ini menunjukkan bahwa Manajemen Berbasis Sekolah meningkat atau ditingkatkan, maka peningkatan ini akan diikuti dengan peningkatan Profesionalitas Guru SMP/MTs Muhammadiyah di Kabupaten Sorong. Artinya semakin efektif Manajemen Berbasis Sekolah, maka akan semakin meningkat Profesionalitas Guru SMP/MTs Muhammadiyah di Kabupaten Sorong.

2. Terdapat pengaruh yang signifikan Iklim Organisasi sekolah terhadap Profesionalitas Guru SMP/MTs Muhammadiyah di Kabupaten Sorong. Adanya pengaruh ini menunjukkan bahwa Iklim Organisasi sekolah meningkat atau ditingkatkan, maka peningkatan ini akan diikuti dengan peningkatan Profesionalitas Guru SMP/MTs Muhammadiyah di Kabupaten Sorong. Artinya semakin kondusiflklim Organisasi sekolah, maka akan semakin meningkat Profesionalitas Guru SMP/MTs Muhammadiyah di Kabupaten Sorong.

3. Terdapat pengaruh yang signifikan Manajemen Berbasis Sekolah terhadap Iklim Organisasi sekolah SMP/MTs Muhammadiyah di Kabupaten Sorong. Adanya pengaruh ini menunjukkan bahwa Manajemen Berbasis Sekolah meningkat atau ditingkatkan, maka peningkatan ini akan diikuti dengan peningkatan Iklim Organisasi sekolah SMP/MTs Muhammadiyah di Kabupaten Sorong. Artinya semakin efektif Manajemen Berbasis Sekolah, maka akan semakin meningkat Iklim Organisasi sekolah SMP/MTs Muhammadiyah di Kabupaten Sorong.

\subsection{Saran}

Berdasarkan dari kesimpulan serta temuan hasil penelitian di lapangan, maka penulis dapat mengajukan beberapa saran sebagai berikut:

1) Karena terdapat pengaruh yang signifikan antara Manajemen Berbasis Sekolah terhadap Profesionalitas Guru SMP/MTs Muhammadiyah di Kabupaten Sorong, maka Manajemen Berbasis Sekolah harus ditingkatkan kualitasnya sebagai bukti pengabdian sekolah-sekolah Muhammadiyah terhadap anak bangsa di kabupaten Sorong, dan pemerintah daerah kabupaten Sorong hendaknya dapat mendukung dengan cara memberikan bantuan baik moral maupun material kepada Sekolahsekolah Muhammadiyah di Kabupaten Sorong.

2) Karena terdapat pengaruh yang signifikan antara Iklim Organisasi Sekolah terhadap Profesionalitas Guru SMP/MTs Muhammadiyah di Kabupaten Sorong, maka kepala-kepala sekolah, guru-guru, komite sekolah dan murid-murid SMP/MTs Muhammadiyah di kabupaten Sorong hendaknya lebih serius dalam 
menjagaIklim Organisasi Sekolah yang kondusif. Pemerintah daerah kabupaten Sorong hendaknya dapat mendukung dengan cara memberikan bantuan baik moral maupun material kepada sekolah-sekolah dalam upaya menjagalklim Organisasi Sekolah yang kondusif.

3) Mengingat pendidikan menjadi tanggung jawab pemerintah pusat, provinsi, kabupaten, dan masyarakat, maka hendaknya pemerintah pusat, provinsi, kabupaten, serta seluruh masyarakat dapat perperan positif dengan cara memberikan bantuan baik fisik maupun non fisik dalam upaya mendukung Profesionalitas Guru SMP/MTs Muhammadiyah di Kabupaten Sorong guna pelaksanaan manajemen berbasis sekolah yang efektif dan efisien.

\section{d) Daftar Pustaka}

Alma, Buchori at al. 2009. Guru Profesional (Menguasai Metode dan Terampil Mengajar). Cet. Ke-2. Penerbit Alfabeta. Bandung.

Anwar, Qomari dan Syaiful Sagala. 2004. Profesi Jabatan Kependidikan dan Guru sebagai Upaya Menjamin Kualitas Pembelajaran. Jakarta: Uhamka Press.

Arikunto, Suharsimi. 2006. Prosedur Penelitian Suatu Pendekatan Praktik, Jakarta: Rineka Cipta.

Bungin, H. M. Burhan. 2009. Metodologi Penelitian Kuantitatif: Komunikasi, Ekonomi, dan Kebijakan Publik Serta Ilmu-ilmu Sosial Lainnya. Jakarta: Kencana.

Agus Dharma. 2003. Manajemen Berbasis Sekolah, Belajar Dari Pengalaman Orang Lain.http://re-searchengines.com/adharma2.html/14/6/2010

Bambangtrie. IKlim Organisasi . http://www.bambangtrie.com/?p=6 2009/03/05

Kunandar. 2008. Guru Profesional Implmentasi Kurikulum Tingkat Satuan Pendidikan (KTSP) dan Sukses dalam Sertifikasi Guru. Edisi I. Jakarta: PT. RajaGrafindo Persada.

Made Pidarta. 2007. Landasan Kependidikan: stimulus ilmu pendidikan bercorak Indonesia. Ed. 2, Cet. 2. Jakarta: Rineka Cipta.

Mulyasa, E. 2007. Manajemen Berbasis Sekolah.cet.11. Penerbit : PT. Remaja Rosdakarya. Bandung.

Murwani, Santosa et. al. 2008. Pedoman Tesis dan Disertasi Program Pascasarjana Universitas Muhammadiyah Prof. DR. HAMKA. UHAMKA PRESS. Jakarta.

Murwani, R. Santosa. 2008. Model Proposal. Program Pascasarjana Universitas Muhammadiyah Prof. DR. HAMKA. Jakarta. 
Murwani, R. Santosa. 2008. Metodologi Penelitian Ilmiah.Program Pascasarjana Universitas Muhammadiyah Prof. DR. HAMKA. Jakarta.

Murwani, R. Santosa. 2008. Statistika Terapan. Jakarta: Program Pascasarjana UHAMKA.

Peraturan Pemerintah Republik Indonesia Nomor 19 Tahun 2005 Tentang Standar Nasional Pendidikan

Prayitno, Irwan. 2008. Profesionalitas Guru di Era Global.http://irwanprayitno.info/artikel/1227678274-profesionalitas-guru-eraglobal.htm/14/6/2010

Purwantini. 2007. Manajemen Berbasis Sekolah. http://manajemenberbasissekolahpurwantini.blogspot.com/2007/07/manajemen-berbasis-sekolah.html/14/6/2010.

Rastodio. 2009.Iklim Sekolah (School Climate).

http://rastodio.com/pendidikan/iklim-sekolah-school-climate.html/14/6/2010

Riduwan dan Sunarto. 2009. Pengantar Statistika untuk Penelitian: Pendidikan, Sosial, Komunikasi, Ekonomi, dan Bisnis. Cetakan ke-2. Bandung: Alfabeta.

Rivai, Veithzal dan Sylviana Murni. 2010. Education Management Analisis Teori dan Praktik. Jakarta: PT. Raja Grafindo Persada.

Rustamadji. 2008. Pengaruh Penyelenggaraan Sekolah Tinggi Keguruan dan Ilmu Pendidikan (STKIP) Muhammadiyah Sorong Dan Manajemen Berbasis Sekolah Terhadap Keberhasilan Otonomi Daerah Bidang Pendidikan Di Kabupaten Sorong. Universitas Satyagama. Jakarta.

Sagala, Syaiful. 2007. Manajemen Strategik Peingkatan Mutu Pendidikan. Penerbit: Alfabeta, CV. Bandung.

Sagala, Syaiful. 2009. Kemampuan Profesional Guru dan Tenaga Kependidikan. Alfabeta, cv. Bandung.

Saudagar, F. dan Ali Idrus. 2009. Pengembangan Profesionalitas Guru. Gaung Persada Press. Jakarta.

Siagian, Sondang P. 1997. Organisasi Kepemimpinan dan Perilaku Administrasi. Jakarta: Toko Gunung Agung.

Soetjipto dan Raflis Kosasi. 2009. Profesi Keguruan. Jakarta: Rineka Cipta.

Sudjana. 1992. Teknik Analisis Regresi dan Korelasi. Bandung: Tarsito.

Sudjana. 2005. Metoda Statistika. Bandung: Tarsito.

Sutisna, Entis. 2009. Iklim Organisasi.

http://gurutisna.wordpress.com/2009/03/05/iklim-organisasi/14/6/2010

Sumarsono, Agus.Antara Tuntutan Profesionalitas Guru/ TenagaPendidik dan PerwujudanKesejahteraan.http://www.kompip.or.id/files/Antara\%20tuntutan\%20p rofesionalitas\%20guru.pdf/14/6/2010 